\title{
Correlation of Foot Wears with MSK Disorders in Ankle Joints Among Females
}

\author{
Dr. Muhammad Tahir Azeem* \\ Consultant Physiotherapist, Health Researcher
}

Dr. Ayesha Ejaz

Doctor of Physical Therapy (DPT), The University of Faisalabad (TUF), Pakistan

Clinical In-Charge, Jinnah Memorial Trust Hospital, Gujranwala, Pakistan

Dr. Faiza Amjad

Assistant Professor, Head of Department,

Department of Physiotherapy Afro Asian Institute, Lahore (Pakistan)

Dr. Maham Khalid

M.Phil (Physiology)-UVAS

Doctor of Physical Therapy (DPT), The University of Lahore (UoL), Pakistan

Lecturer, Afro Asian Institute, Lahore (Pakistan), Physiotherapist (Saima Medical Center)

Dr. Saira Aslam

Lecturer, Afro Asian Institute, Lahore (Pakistan), CEO Multi Talented Medicos

\begin{abstract}
AIM: This paper is a report of study conducted to explain the factors that causes ankle sprain by wearing high heels among students of Sargodha medical college and university of Sargodha.BACKGROUND: High heeled shoes have been worn for several centuries and despite numerous cautions against their use, they remain extremely popular. Wearing high heeled shoes is thought to increase the individual's likelihood of experiencing a lateral ankle sprain. The $19^{\text {th }}$ century saw the first warnings that wearing high heels footwear could lead to trips and falls. Previous investigations have shown that high heeled shoes align the foot in planter flexion, modifying the relative orientation of the skeletal structures of ankle, midtarsal, and metatarsophalangeal joints, and alter the insertion angles of the foot and gliding joint muscles, therefore increasing the risk factor for ankle sprain.METHODS: observational non-experimental study was conducted via a questionnaire which was distributed among 500 female students of SMC (Sargodha medical college) and university of Sargodha. These female students fall in age group between18-26.RESULT: The result of our study concluded that the types of heel and height of heel are the most significant factors that cause ankle sprain. The ankle sprain caused by wearing pencil heels and by use of $<3$ inch heels are greatest.
\end{abstract}

Keywords: Pencil heel, height of heel, Ankle sprain, SMC, Female student.

DOI: $10.7176 / \mathrm{JHMN} / 80-09$

Publication date:September $30^{\text {th }} 2020$

\section{INTRODUCTION}

High-heeled shoes are defined as shoes in which the heel is higher than the forepart. High-heeled shoes often also include a narrow toe box, rigid heel cap, and curved plantar region, all of which interfere with natural foot motion. High-heeled shoes have been worn for several centuries[1] and despite numerous cautions against their use, they remain extremely popular.

The preference for high heeled footwear by women has been a concern to health professionals since the 18th century[2],[3]. The 19th century saw the first warnings that wearing high heeled footwear could lead to trips and falls[4]. Since this time, women have also been warned about the possibility for long term foot change from wearing high heeled footwear including shortened calf muscles, clawed toes, sprained ankles, bunions and foot pain[4].

Surveys suggest that $37 \%$ and $69 \%$ of women wear them in their daily lives, representing a huge proportion of the female population [5]. Wearing high heel shoes is thought to increase an individual's likelihood of experiencing a lateral ankle sprain [6].Ankle sprain accounts for between 3\% and 5\% of all Emergency Department visits in the UK, equating to approximately 5,600 incidences per day [7].Previous investigations have shown that high-heeled shoes align the foot in plantarflexion;modifying the relative orientation of the skeletal structures of the ankle, midtarsal, and metatarsophalangeal joints; and alter the insertion angles of the foot and gliding joint muscles [8],therefore increasing the risk factor for ankle sprain. 


\section{LITERATURE REVIEW}

SM Younasand his colleagues 2014 conducted a study about outcomes of wearing high heeled shoes in young generation in Pakistan. They found that out of the total participants $18.8 \%$ experience foots welling, $19.4 \%$ blisters, $16.4 \%$ foot numbness, $12.3 \%$ foot callosities, $2.8 \%$ heel spur, and $3.7 \%$ experience bunions. From this study conducted on the students of medical college it was found that wearing high heel shoes is not associated with any significant complications among most of the students.[9]

Ebbeling and his colleagues ,1994 found that wearing of heels higher than $5.08 \mathrm{~cm}$ significantly increased heart rate and oxygen consumption, leading the authors to recommend that only heels lower than this height should be worn under the assumption that wearing a higher heel may fatigue the wearer and therefore result in injuries[10].

Lee and his colleagues ,2001 found that the higher the heel, the greater the ankle inversion moment[11]. These authors argued that wearing high heeled footwear placed the ankle at greater risk for inversion sprain injury simply due to this anatomical positioning. Further, a survey of two hundred women who regularly wore high heeled footwear, found that approximately half of the women suffered from back pain and felt limited in their everyday activity when wearing a heel between $6 \mathrm{~cm}-9 \mathrm{~cm}$ of height[12]

Foster and his colleagues, 2012 reported that the planter flexed and inverted posture of foot when wearing high heels increased an individual's risk for experiences a lateral ankle sprains.[11]

Moore and his colleagues, 2015 investigated the epidemiology of high-heel-related injuries associated with ankle sprain in the U.S among a population of women to analyze the demographic differences. A data used in the present study were collected from the Consumer Product Safety Commission's National Electronic Injury Surveillance System. A total of 3294 injuries, representing an estimated 123,355 high-heel-related injuries, were treated in emergency departments within the United States from 2002 to 2010.The overall rate of high-heelrelated injuries for the study was 7.32 per 100,000 females ( $95 \%$ confidence interval 7.08 to 7.56 ). The injury rate was greatest for young adult females, with the greatest rates observed for those aged 20 to 29 years(18.38 per 100,000 females) and those aged 30 to 39 years(11.07 per 100,000 females).

The results from present study suggest that high-heel-related injuries have nearly doubled during the 11 year period from 2002 to 2012. Injuries from high heels are differential with most injuries occurring as sprains and strains to the foot and ankle. The results of this study can be used in the development of a prospective cohort study to investigate the risk of injury from high-heeled shoes, accounting for the exposure time and studying differences in demographics such as race and age.[13]

Yeoletand his colleagues, 2013 [31] investigated the effects on the displacement of center of pressure (COP). He observed also the distribution of foot pressure and concluded that high heels showed adverse functional effects on ankle sprain especially in college students in their 20s.[14]

Rebecca E. Snow and his colleagues, 1992 study the effects of increased heel height in women's shoes on foot pressure during walking. This study may denote increased stress to the various tissues in the foot when walking in high heeled shoes, which may contribute to deleterious orthopedic changes.[15]

Snow RE,Williams KR.,1994 studied changes in centre of mass position, forefoot loading, lumbar curvature, and pelvic tilt during standing and ground reaction forces, rear foot motion, sagittal lower extremity kinematics, and shoulder and pelvic rotations of women walking at $1.4 \mathrm{~m} . \mathrm{s}-1$ in different heights of high heeled shoes. They found that rear foot angle measures obtained from high-speed video analysis showed a significantly greater angle of supination at foot strike and a smaller angle of maximum pronation in the high compared with the low heeled shoes. Ankle angles throughout the gait cycle showed a significant increase in plantar flexion with increased heel height. [16]

AH Hansen and his colleagues, 2004 studied the effects of shoes heel height on the rollover characteristics of the biologic ankle-foot system. The results supports the notion that nondisabled human automatically adapt their ankle-foot systems to accommodate a range of shoe heel heights, resulting in rollover shapes that do not change appreciably.[17]

LY Guoet al., 2012 studied the effects on planter pressure distribution with wearing different base size of high-heel shoes during walking and slow running. Results show that the plantar pressures of the hallux and toe while wearing narrow base high heel were greater than those when walking with wearing wide base one. For both narrow and wide base heels, significantly increased plantar pressure were found in the medial forefoot while slow running as compared with walking. While slow running with wearing narrow base high heel indicated significantly increased plantar pressures in the medial, central and lateral forefoot and toes regions compared with those with wearing wide base one. The findings suggest that if individuals have to wear high heeled shoes, it would be better to select one with a wide based heel to avoid running in at any circumstance.[18]

\section{PURPOSE OF STUDY}

$>$ To determine the factors causing ankle sprain as a result of wearing high heels.

$>$ To find out which type of heel cause ankle sprain due to use of high heels. 
To find out which height of heel contributes more in causing ankle sprain due to use of high heels.

\section{METHODOLOGY}

\section{Study design:}

Cross sectional study.

Study Setting:

University of Sargodha and Sargodha medical college.

Sample size:

500 female students.

Inclusion criteria:

Female students from age 18-26.

\section{Exclusion criteria:}

Female students with any congenital ankle problem and female students from any college other than University of Sargodha and Sargodha medical college.

Method: Self-constructed Questionnaire

\section{STATISTICAL ANALYSIS}

Data was compiled via SPSS. We took sample set of 500 female students. According to SPSS analysis the dependent variable is type of heel and independent variable is age of student.

\section{a. Age Factor:}

In our study, we collected data from 500 girls of different age groups and according to our data the most frequent age group that are using high heels are of age 22 years, this age group carries 27.2 percent of the total percent. Other age groups that are mostly using high heels are of age 21 years and 23 years of girls. Our descriptive statistics shows that the minimum age group in our study is of 18 years of girls and maximum age is $26 y e a r s$. The mean of age group is 21.95 it means that mostly this age group took part in our study.

\section{b. Weight Factor}

Weights vary according to age and height. Weight was asked from our subjects. The highest frequency that we got according to our study is of weight $\mathbf{5 0}$ whose frequency was 61 . That is of girls who weigh $50 \mathrm{~kg}$ they carry 12.2 percent of the total subjects. However the results indicate that minimal weight changes do not significally affect our results.

\section{c. Height Factor}

In our study we collected data of 500 people who have different ages and heights and according to our study, the girls of height 5.3 inches are most frequent and the frequency of this height group is 130 and it carries 26 percent of the total subjects. Other height groups which are frequent according to our study are 5.2 inches and 5.4 inches and their frequencies are 123 and 56 respectively.

\section{d. Duration of Using High Heels}

500 girls of different age and height were asked about the regular duration of using high heels and according to our study, the girls using high heels for 4-6 hrs regularly are most frequent and they carries 50 percent of the total.

\begin{tabular}{|c|c|c|c|c|c|}
\hline \multicolumn{6}{|c|}{ What is the duration of using high heels? } \\
\hline & & Frequency & Percent & Valid Percent & Cumulative Percent \\
\hline \multirow[t]{4}{*}{ Valid } & $1-3$ & 180 & 36 & 36 & 36 \\
\hline & 4-6 & 250 & 50 & 50.0 & 80 \\
\hline & 6-8 & 70 & 14 & 14 & 100.0 \\
\hline & Total & 500 & 100.0 & 100.0 & \\
\hline
\end{tabular}

Table 1: Duration of Using High Heels. 


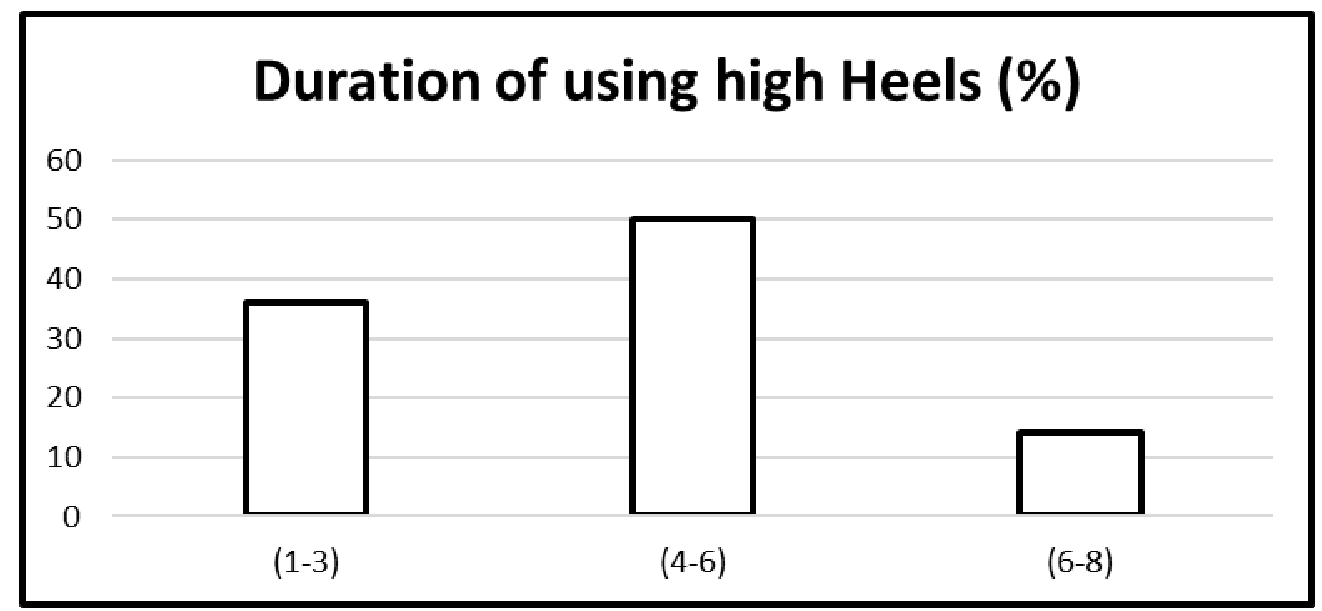

\section{e. Height of Heels}

The result shows that $32.6 \%$ were wearing $<2$ inches heels, $50.8 \%$ were wearing $<3$ inches and $16.6 \%$ were wearing 4-5 inches heel.

\begin{tabular}{|c|c|c|c|c|c|}
\hline \multicolumn{6}{|c|}{ What is the usual height of heel? } \\
\hline & & Frequency & Percent & Valid Percent & Cumulative Percent \\
\hline \multirow[t]{4}{*}{ Valid } & $<2$ & 163 & 32.6 & 32.6 & 32.6 \\
\hline & $<3$ & 254 & 50.8 & 50.8 & 83.4 \\
\hline & $4-5$ & 83 & 16.6 & 16.6 & 100.0 \\
\hline & Total & 500 & 100.0 & 100.0 & \\
\hline
\end{tabular}

Table 2: Usual Height of Heel.

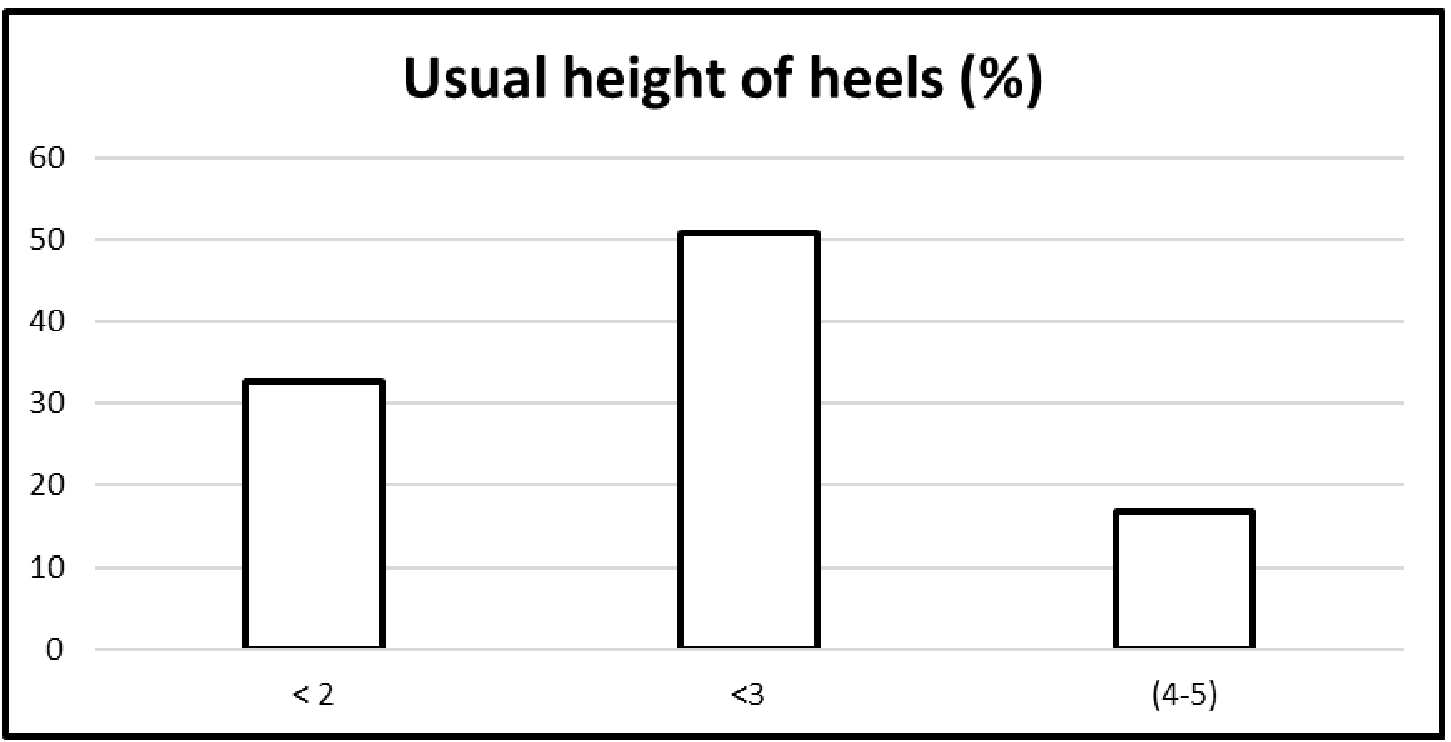

According to our study, the most frequently used heels are pencil heels. The result shows that $22.0 \%$ wearing wedge heel, $45.6 \%$ were wearing pencil heels, $28.4 \%$ were wearing sole heel and $4 \%$ wearing block heels. 


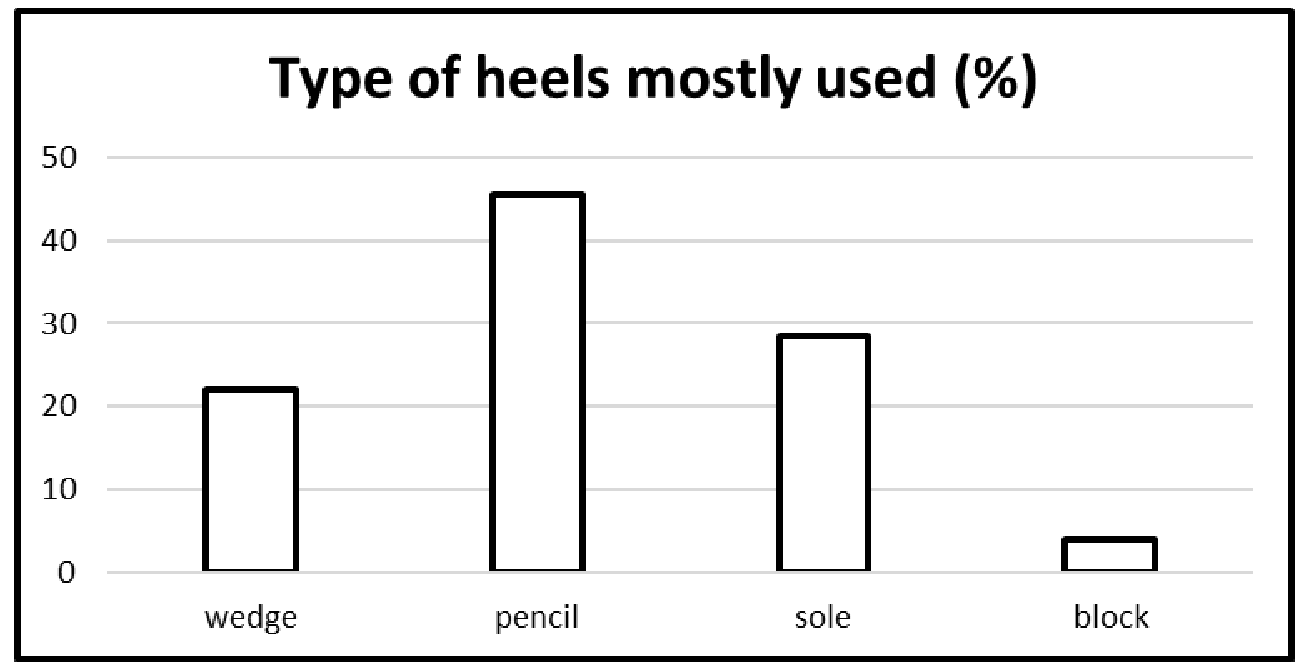

\begin{tabular}{|l|l|c|c|c|c|}
\hline \multicolumn{7}{|c|}{ Which type of heel you mostly use? } \\
\hline \multirow{3}{*}{ Valid } & Frequency & Percent & Valid Percent & Cumulative Percent \\
\cline { 2 - 6 } & pencil & 110 & 22.0 & 22.0 & 22.0 \\
\cline { 2 - 6 } & sole & 228 & 45.6 & 45.6 & 67.6 \\
\cline { 2 - 6 } & block & 142 & 28.4 & 28.4 & 96.0 \\
\cline { 2 - 6 } & Total & 20 & 4.0 & 4.0 & 100.0 \\
\hline
\end{tabular}

\section{f. Purpose of Using High Heels}

Table 3: Type of Heels

Analysis indicates that the girls who mostly used high heels to increase confidence are most frequent. The result shows that $36 \%$ wearing heel to increase female attractive, $20.2 \%$ were wearing heels to increase confidence and $43.8 \%$ were wearing heel to feel comfortable.

Purpose of wearing heels?

\begin{tabular}{|l|l|c|c|c|c|}
\hline \multicolumn{2}{|c|}{} & & & & \\
\hline \multirow{3}{*}{ Valid } & Attractiveness & 180 & 36 & 36 & Cumulative Percent \\
\cline { 2 - 6 } & Confidence & 101 & 20.2 & 56.2 & 20.2 \\
\cline { 2 - 6 } & Comfortable & 219 & 43.8 & $43 . .8$ & 62.0 \\
\cline { 2 - 6 } & Total & 500 & 100.0 & 100.0 & 100 \\
\hline
\end{tabular}

Table 4: Purpose of Wearing Heels

\section{Purpose of wearing high heels (\%)}

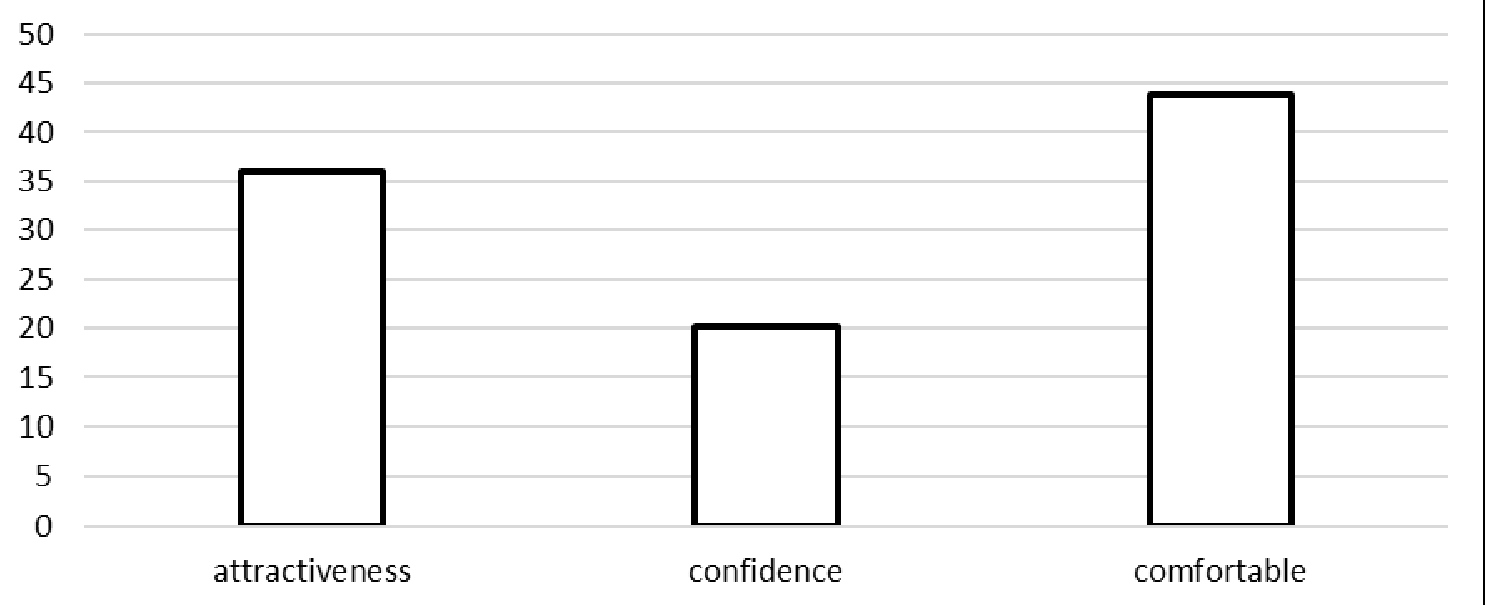




\section{g. Do High Heels Hurt}

The result shows that $62 \%$ are in the favor of hurting heel by high heel while other $38 \%$ disagree with that point.

\begin{tabular}{|l|l|c|c|c|c|}
\hline \multicolumn{5}{|c|}{ Do high heels hurt your heels? } \\
\hline \multirow{3}{*}{ Valid } & Yes & 390 & 62 & 62 & Cumulative Percent \\
\cline { 2 - 6 } & No & 110 & 38 & 38 & 62 \\
\cline { 2 - 6 } & Total & 500 & 100.0 & 100.0 & 100 \\
\hline
\end{tabular}

Table 5: High Heels Hurt Your Heels

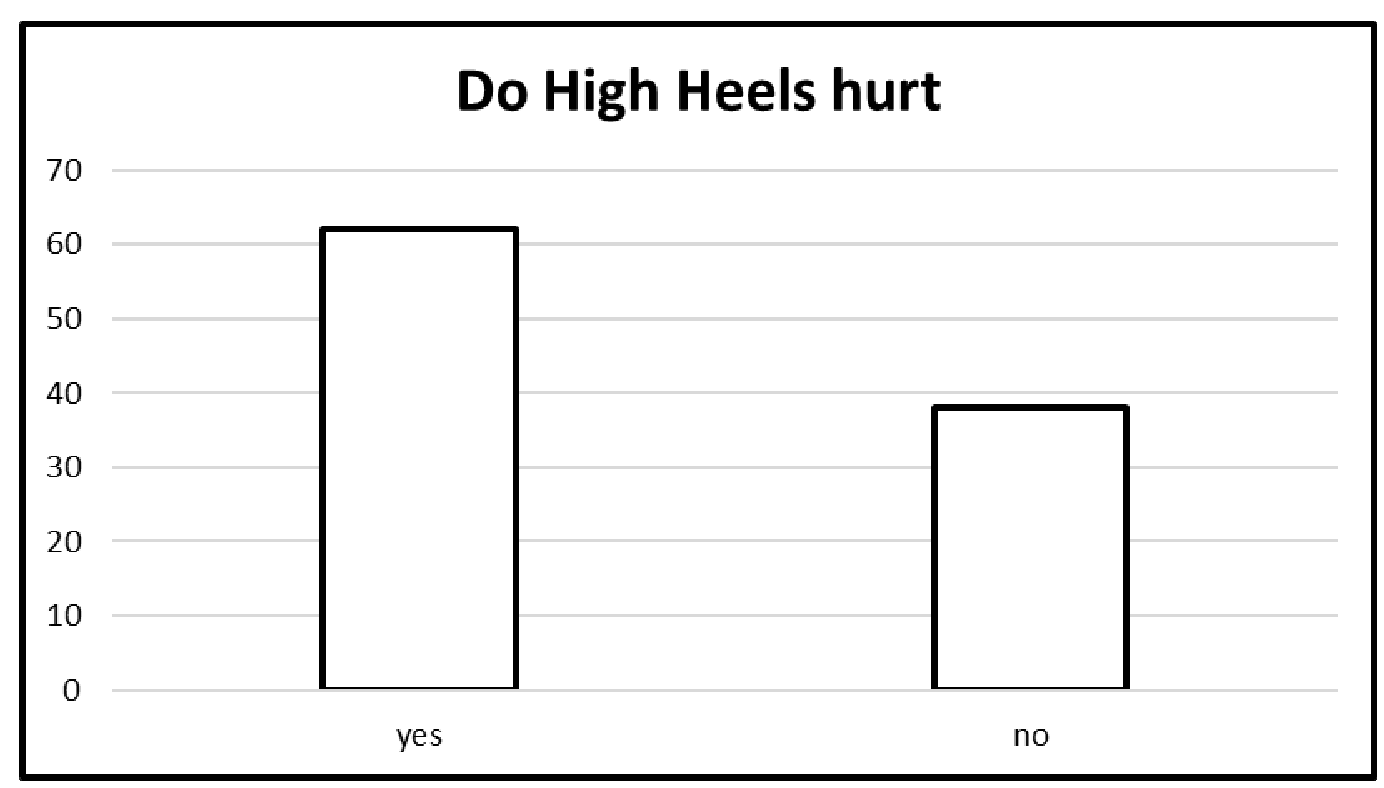

h. Which Ankle Sprains Most

Analysis shows that the girls who are using high heels have mostly sprained their right ankle are most frequent. The result shows that $43 \%$ are in the favor of right ankle sprained, 33\% are in favors of left ankle while remaining $24 \%$ are in the favors of both ankles sprained.

\begin{tabular}{|c|c|c|c|c|c|}
\hline \multicolumn{6}{|c|}{ Which ankle you mostly sprained? } \\
\hline & & Frequency & Percent & Valid Percent & Cumulative Percent \\
\hline \multirow[t]{4}{*}{ Valid } & right & 215 & 43 & 43 & 43 \\
\hline & left & 165 & 33 & 33 & 77 \\
\hline & both & 120 & 24 & 24 & 100 \\
\hline & Total & 500 & 100.0 & 100.0 & \\
\hline
\end{tabular}

\section{Which ankle you most sprained(\%)}

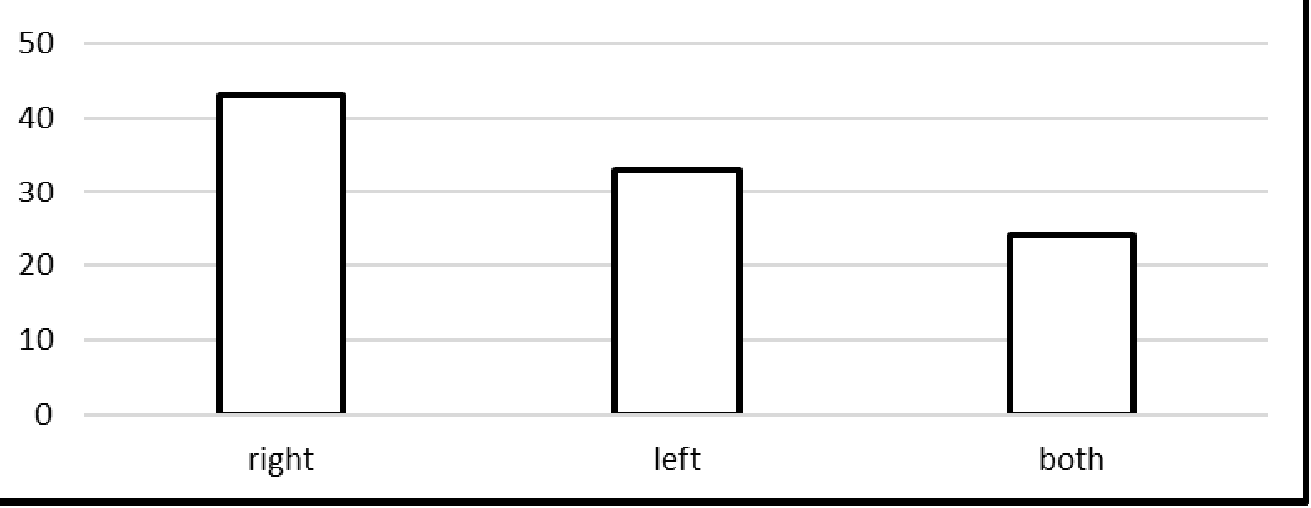

i. Which Heel Causes Twisting of Foot

The collected data from 500 girls indicates that $16 \%$ are in the favor of wedge heel twisting, $62.2 \%$ are in favors pencil heels, $1.6 \%$ in the favor sole heel and other $20.2 \%$ were in the favor of block heel. 
Which type of heel mostly Cause twisting of your foot?

\begin{tabular}{|l|l|c|c|c|c|}
\hline \multicolumn{9}{|c|}{ Which type of heel mostly Cause twisting of your foot? } \\
\hline \multirow{3}{*}{ Valid } & Frequency & Percent & Valid Percent & Cumulative Percent \\
\cline { 2 - 6 } & wedge & 80 & 16.0 & 16.0 & 16.0 \\
\cline { 2 - 6 } & pencil & 311 & 62.2 & 62.2 & 78.2 \\
\cline { 2 - 6 } & sole & 8 & 1.6 & 1.6 & 79.8 \\
\cline { 2 - 6 } & block & 101 & 20.2 & 20.2 & 100.0 \\
\cline { 2 - 6 } & Total & 500 & 100.0 & 100.0 & \\
\hline
\end{tabular}

Table 7: Cause Twisting of Your Foot

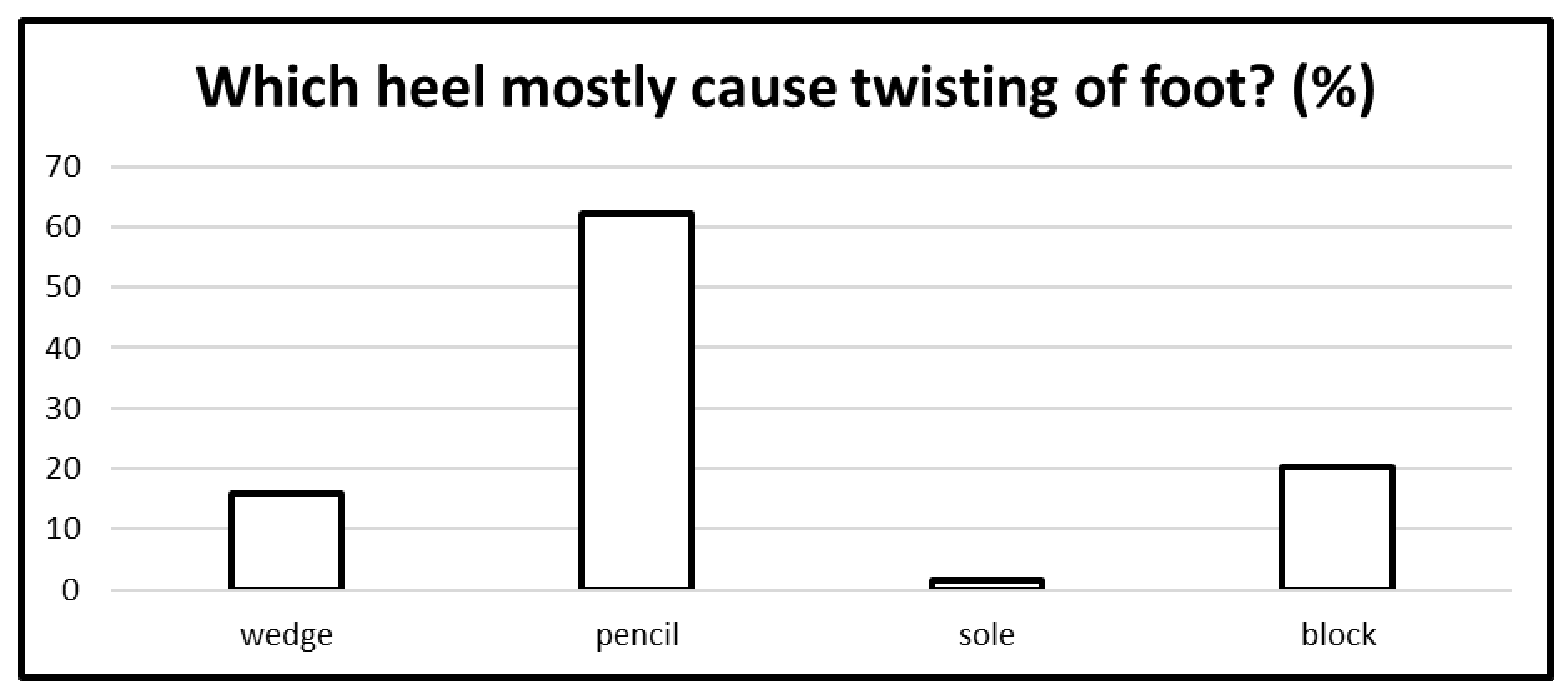

j. How Often Have You Experienced Ankle Sprain

The result shows $13 \%$ responses rarely to ankle sprain, 54\% responses mostly and 33\% responses towards not often.

\begin{tabular}{|l|l|c|c|c|c|}
\hline \multicolumn{9}{|c|}{ How often you experience ankle sprain? } \\
\hline \multirow{3}{*}{ Valid } & Frequency & Percent & Valid Percent & Cumulative Percent \\
\cline { 2 - 6 } & Mostly & 65 & 13 & 13 & 13 \\
\cline { 2 - 6 } & not so often & 270 & 54 & 54 & 67 \\
\cline { 2 - 6 } & Total & 165 & 33 & 33 & 100 \\
\hline
\end{tabular}

Table 8: Experience Ankle Sprain

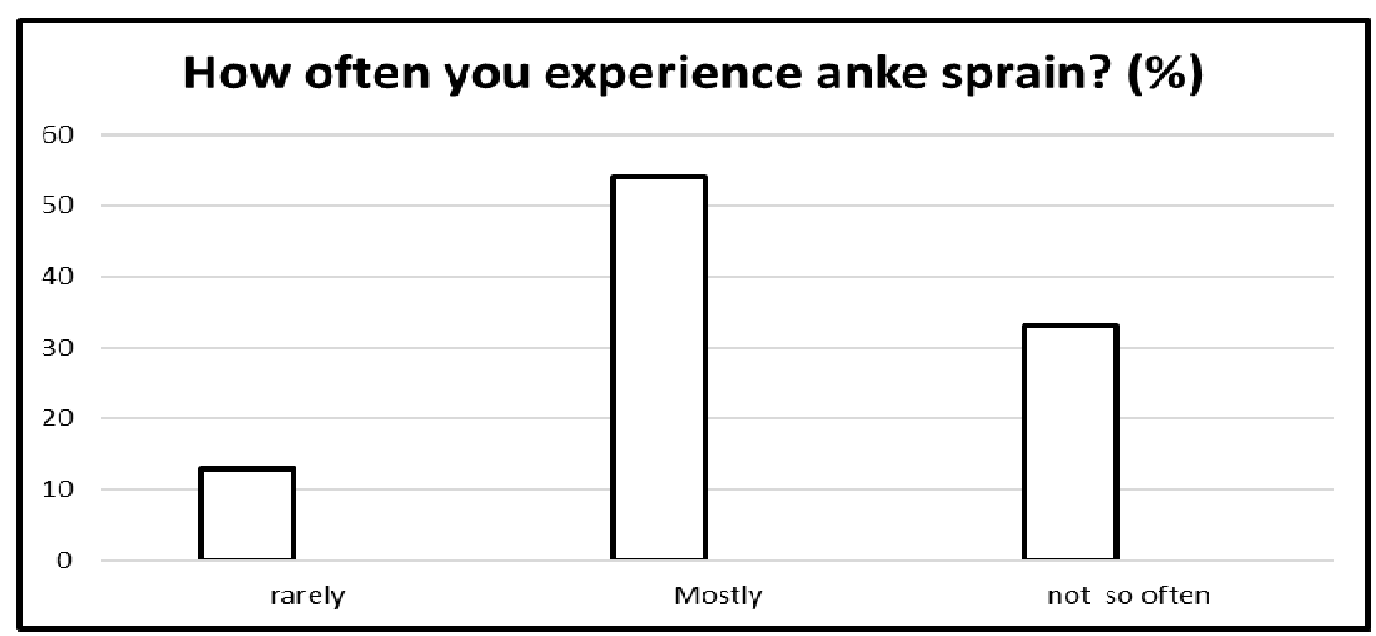

k. Any Other Type of Foot Pathology Experienced

We collected data from 500 girls and we asked them about any other foot pathology by using high heels. The result shows $33.2 \%$ responses towards bi-union, $42 \%$ responses metatarsalgia and $24.8 \%$ responses towards hammertoes. 


\begin{tabular}{|c|c|c|c|c|c|}
\hline \multicolumn{6}{|c|}{ Have you ever experienced any other foot pathology by wearing high heels? } \\
\hline & & Frequency & Percent & Valid Percent & Cumulative Percent \\
\hline \multirow[t]{4}{*}{ Valid } & Bi-union & 166 & 33.2 & 33.2 & 33.2 \\
\hline & Metatarsalgia & 210 & 42.0 & 42.0 & 75.2 \\
\hline & Hammertoes & 74 & 24.8 & 24.8 & 100.0 \\
\hline & Total & 500 & 100.0 & 100.0 & \\
\hline
\end{tabular}

Table 9: Other Foot Pathology by Wearing High Heels

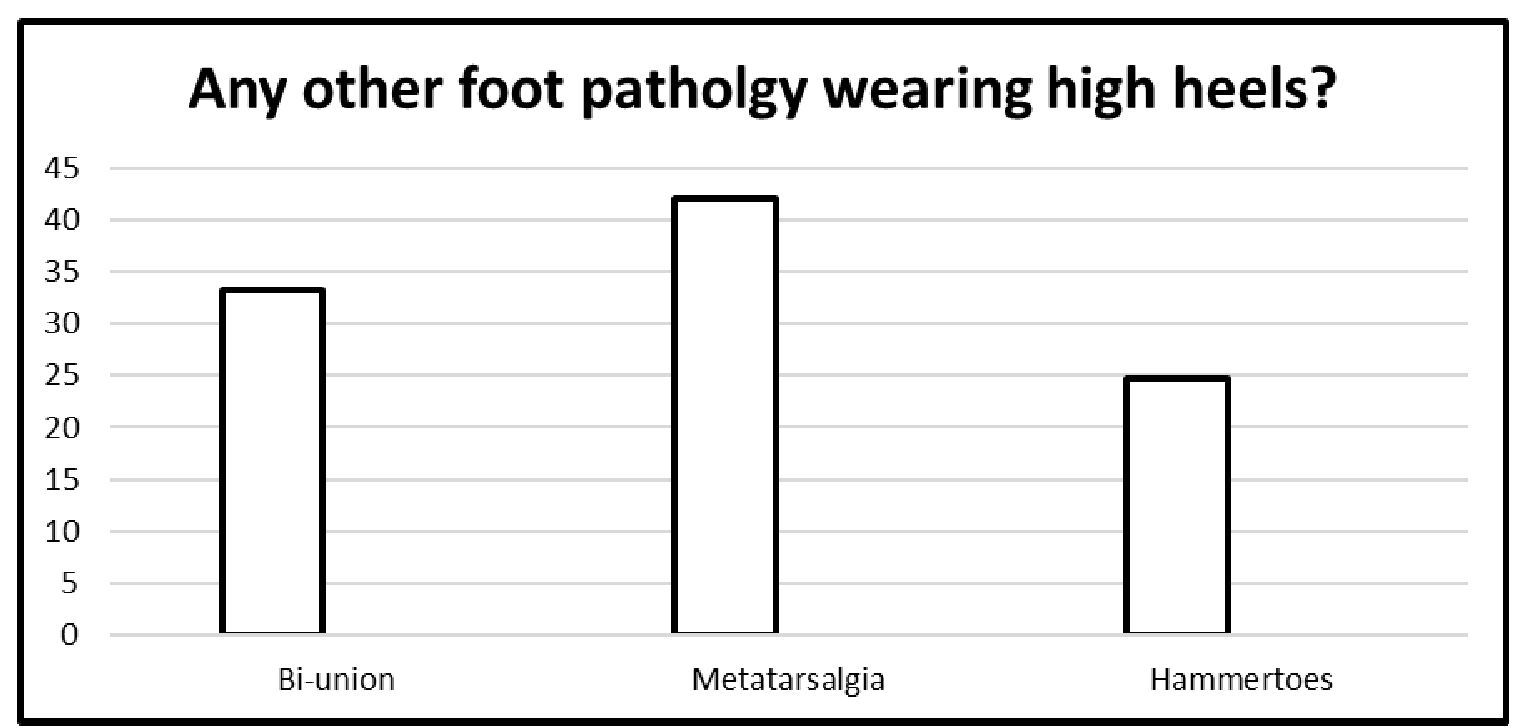

1. Do You Have Miscellaneous Following Problems

The result shows $37.8 \%$ responses towards instability, $26 \%$ responses towards decrease ambulation and $36.2 \%$ responses towards feeling pain. They are shown in the graph.

Do you have any of the following problems?

\begin{tabular}{|l|l|c|c|c|c|}
\hline \multicolumn{2}{|c|}{} & & & & \\
\hline \multirow{3}{*}{ Valid } & En-stability & 189 & 37.8 & 37.8 & Cumulative Percent \\
\cline { 2 - 6 } & Decrease Ambulation & 130 & 26.0 & 26.0 & 37.8 \\
\cline { 2 - 6 } & Feeling Pain & 179 & 36.2 & 36.2 & 61.8 \\
\cline { 2 - 6 } & Total & 500 & 100.0 & 100.0 & 100 \\
\hline
\end{tabular}

Table 10: Others Problems

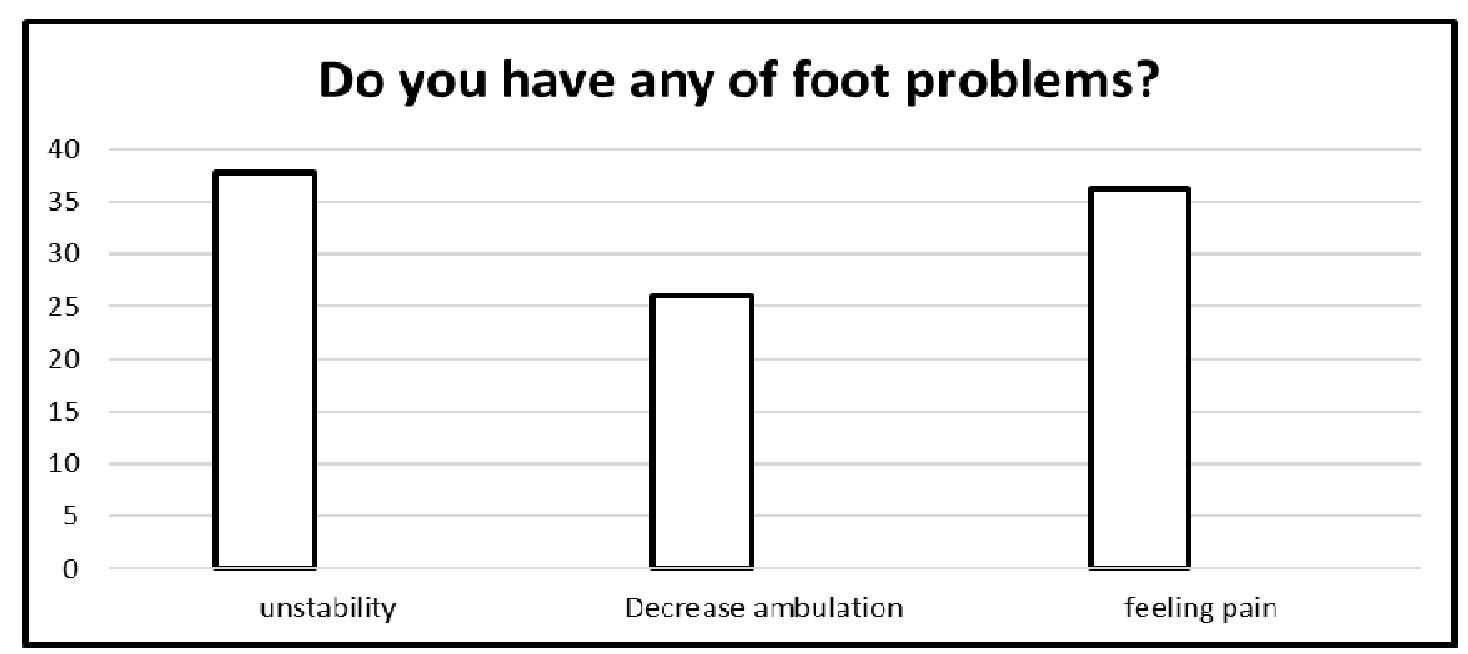

\section{RESULT}

In case of dependent variable set as DO HIGH HEELS HURT YOU, SPSS analysis indicate that most significant factors that are hurting the ankle by using high heels are type of heels and age of person .type of heels 
is the most significant factor that $r$ contributing 0.79 in hurting your ankle. The $2^{\text {nd }}$ significant factor is the height of heels that contributes about 0.691 in hurting the ankle.

According to our study, the most frequently used heels are pencil heels and the ankle sprain caused by wearing pencil heels are most frequent as compared to other heels. Pencil heels cause twisting of foot mostly hence the chances of ankle sprain by the use of pencil heel are greatest.

Which type of heel mostly cause twisting of your foot?

\begin{tabular}{|l|l|c|c|c|c|}
\hline \multicolumn{2}{|l|}{} & Frequency & Percent & Valid Percent & Cumulative Percent \\
\hline \multirow{7}{*}{ Valid } & Wedge & 80 & 16.0 & 16.0 & 16.0 \\
\cline { 2 - 6 } & Pencil & 311 & 62.2 & 62.2 & 78.2 \\
\cline { 2 - 6 } & Sole & 8 & 1.6 & 1.6 & 79.8 \\
\cline { 2 - 6 } & block & 101 & 20.2 & 20.2 & 100.0 \\
\cline { 2 - 6 } & Total & 500 & 100.0 & 100.0 & \\
\hline
\end{tabular}

Table 11: Cause Twisting of Your Foot

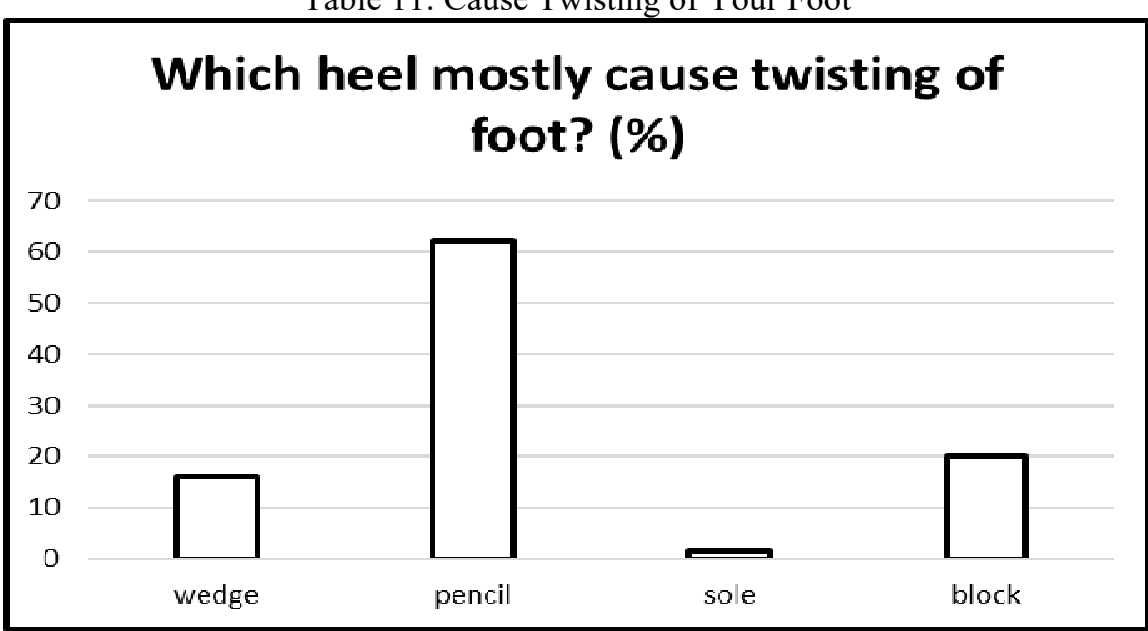

The result shows that $50.8 \%$ were wearing $<3$ inch heel which mostly cause twisting of foot and ankle sprain. And according to our SPSS analysis height of heels is the significant factor that are causing the ankle sprain.

What is the usual height of heel?

\begin{tabular}{|l|l|c|c|c|c|}
\hline \multicolumn{2}{|c|}{} & Frequency & Percent & Valid Percent & Cumulative Percent \\
\hline \multirow{3}{*}{ Valid } & $<\mathbf{2}$ & 163 & 32.6 & 32.6 & 32.6 \\
\cline { 2 - 6 } & $<\mathbf{3}$ & 254 & 50.8 & 50.8 & 83.4 \\
\cline { 2 - 6 } & $\mathbf{4 - 5}$ & 83 & 16.6 & 16.6 & 100.0 \\
\cline { 2 - 6 } & Total & 500 & 100.0 & 100.0 & \\
\hline
\end{tabular}

Table 12: Usual Height of Heel

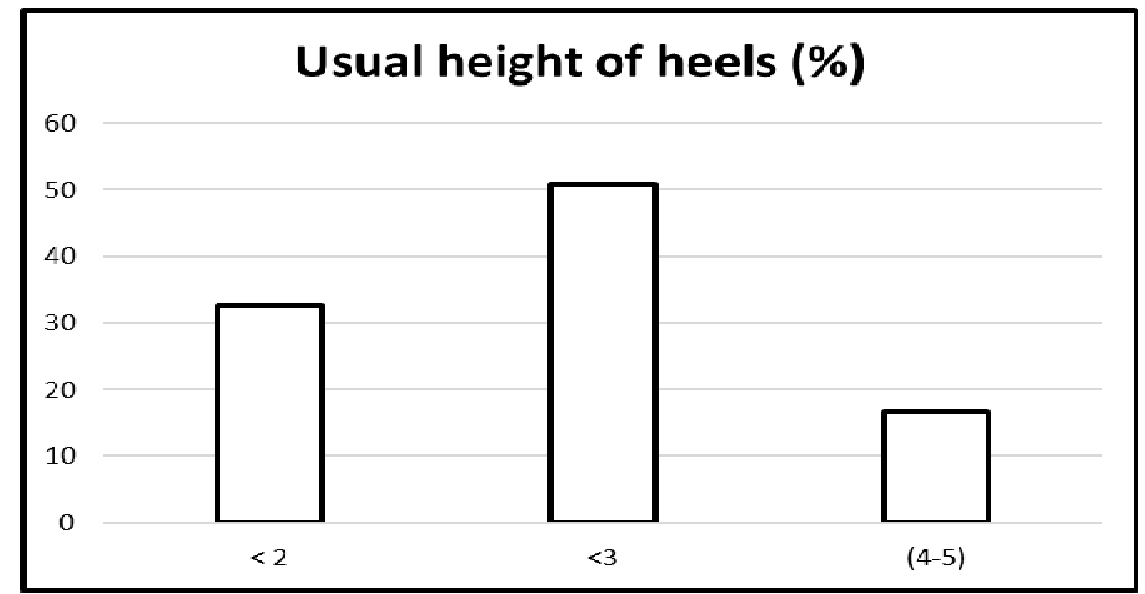




\begin{tabular}{|c|c|c|c|c|c|}
\hline \multicolumn{6}{|c|}{ Coefficients $^{\mathrm{a}}$} \\
\hline \multirow[b]{2}{*}{ Model Heels } & \multicolumn{2}{|c|}{ Unstandardized Coefficients } & \multirow{2}{*}{$\begin{array}{c}\text { Standardized Coefficients } \\
\text { Beta } \\
\end{array}$} & \multirow[b]{2}{*}{$\mathbf{t}$} & \multirow[b]{2}{*}{ Sig. } \\
\hline & $\mathrm{B}$ & Std. Error & & & \\
\hline 1 (Constant) & 1.794 & .689 & & 2.605 & .009 \\
\hline AGE & .005 & .014 & .018 & .397 & .513 \\
\hline WEIGHT & -.003 & .004 & -.038 & -.840 & .402 \\
\hline HEIGHT & -.082 & .114 & -.032 & -.714 & .475 \\
\hline HEIGHT OF YOUR HEEL & .112 & .030 & .167 & 3.733 & .619 \\
\hline TYPE OF HEEL & -.008 & .027 & -.014 & -.307 & .759 \\
\hline
\end{tabular}

a. Dependent Variable: DO HIGH HEELS HURT YOU

\section{Table 13: Coefficients}

According to our study and SPSS analysis type of heels and height of heels are the most significant factors in causing the ankle sprain and in type of heels pencil heels are the most frequently used heels and pencil heels are the main cause of twisting of foot and ankle sprain and among height of heels $<3$ inch height are used by the girls of age 18-26 which are causing the ankle sprain.

\section{VII.DISCUSSION}

High heels have long been a symbol of a sophisticated woman. From Marilyn Monroe to Carrie Bradshaw, heels have been worn by fashion-minded women for quite some time now, and they've become synonymous with style and luxury. However, this particular accessory is not without its downfall, and looks like the popular saying was right: Beauty is pain. High heels can have a number of long-lasting negative health effects on the body, extending just beyond the foot.

Here we discuss some effects that are caused by use of high heels.

High heels cause damage to toes and nails. According to Lyolamedicine high heels are the leading cause of ingrown toe nails. This occurs because the toes compress together, causing the big toe nails to grow into the skin. This can also lead to nail or fungal infections.

High heels can cause bi unions. Because use of high heels can tip your body weight forward, forcing the toes towards the front of the shoe. This action pushes the big toes against the other toes, which can cause the bunion protrusion

High heels can cause hip and knee pain. It is the most common problem that many girls experienced while using high heels. Walking in high heels increases the amount of weight put on the knee joints, as women tend to bend their knees more while walking in high heels shoes. This can strain knee joints as well as the hip, and exert extra pressure on these joints and due to its excessive use it can trigger fractures and compresses the nerves.

Regular use of high heels increases the risk of osteoarithritis, which is the inflammatory joint condition in women of old age bt the prolonged use of high heels can increase the risk of osteoarithritis. According to the study of Orthopedic journal women wearing heels higher than 3.5 inches can increase the lifetime risk of osteoarithritis.

The most common complaint from girls wearing high heels are about muscle pain and spasm. Long-term wear of high heels can shorten the muscles in calves and in back, which can cause muscle pain and spasms, according to the American Osteopathic Association. Many women also experience and complain of painful leg cramps after wearing the high heels shoes.

It is a common experience that there is usually a less support and comfort in high heels. The high heels exert a constant pressure on the balls of your feet which causes weight distribution to be less even and lower back pain often results. Nerves can also become stressed in the lower back because of the odd posture while wearing high heels. Resting the body weight on balls of feet cause worsening pain after some time. Walking around on the balls of feet all day tend can create yellowed areas on bottom of feet that remains sore after high heels are removed.

High heels effects the natural curve of spine. The lower back becomes even more arched than usual when you wear high heels. The higher the height of heels are, the more the lower back has to arch to keep the positioned upright. This extreme curve is a contributor to back pain in both the lower and the upper region.

We conducted a study about high heels that regular use of high heels cause ankle sprain. We collected data from 500 girls of different age and according to our study and statistical analysis, height of heels and type of heels is the most significant factors that are causing ankle sprain. Type of heels is the main factor which is causing the ankle sprain. As we know that heel height greater than 1.5 inches can cause changes in the body so the girls using high heels regularly, more often suffer from ankle sprain than other girls. As height of heels can change the mechanics of the body while walking, it can exert greater pressure on ankle and other joints as well. So while using high heels during ambulation due to greater forces and stresses exert on the foot the high heels causes twisting of your foot which can cause ankle sprain. Age also plays an important factor in twisting of foot 
because with age the body is unable to maintain balance and while using high heels balance of person lost and person may fall and results in twisting of foot and ankle sprain while walking with high heels.

High heels hurt the ankle mostly and according to our study the most significant factor of causing ankle sprain and hurting your ankles are type of heels and height of heels. Type of heels also plays the significant role in hurting the feet. There are different types of heels in the market and different girls prefer different heels according to their choices. According to our data analysis, pencil heels are the most frequently used heels by girls and while using pencil heels the balance of girls is lost and ankle is hurt mostly which in turn leads to spraining of ankle.

High heels, whether stilettos, wedges, or pumps, have been fashionable for decades. Many women don't feel dressed for work if they aren't wearing high heels with their business suits. And dressing up for a special event almost always involves stepping out in heels. While high heels add inches to height and make legs look longer and sleeker the eventual result of wearing these shoes much of the time may not be a pretty picture. In fact, high heels can put your health in danger. Sprains and strains to the foot and ankle were the most common complaints, and most patients were in their 20s and 30s, the study found. "Although high-heeled shoes might be stylish, from a health standpoint, it would be worthwhile for those interested in wearing high-heeled shoes to understand the risks and the potential harm that precarious activities in high-heeled shoes can cause," said the study's lead investigator, Gerald McGwin, an epidemiology professor in the UAB School of Public Health, in a university news release. Not surprisingly, young women in their 20 s were most likely to get these injuries, which were usually sprains and strains to the foot or ankle. What is surprising is that half of these injuries happened at home, not at work or out on the town. In the study, which is published in the Journal of Foot and Ankle Injuries, researchers recommend you think about the risks to your safety before you strap on those six-inch stilettos.

The study conducted in SMC has some limitations. The foremost is that in this study data was collected and analyzed only from the girls of Sargodha Medical College and University of Sargodha. Our study was confined to specific age group i.e. 18-26.Furthermore, it does not address the effects of high heels on other parts of body such as knee, hip and spine etc. Our survey was evaluated through self-made questionnaire not by clinical analysis.

\section{CONCLUSION}

According to our study and statistical analysis the types of heel and height of heels are the most significant factors that are causing the ankle sprain while using the high heels:-

$>54 \%$ female experience ankle sprain mostly

$>13 \%$ experience ankle sprain rarely.

$>33 \%$ not often experience ankle sprain.

According to our study and ankle sprain caused by wearing heels of

$><2$ inch is $32.6 \%$

$><3$ inch is $50.8 \%$

$>\quad 4-5$ inch is $16.6 \%$

According to our study the ankle sprain caused by wearing

$>$ Pencil heel is $62.2 \%$

$>$ wedge heel is $16 \%$

$>$ Sole heel is $1.6 \%$

$>$ Block heel is $20.2 \%$

\section{RECOMMENDATION:}

$>$ Study should be analyzed through clinical analysis in future.

$>$ Seminars can be conducted to spread the awareness among females.

$>$ Study should also be conducted on females above 30 years of age in future.

$>$ Research should also include the aspect of brand and quality of shoes.

$>$ Longitudinal study should be conducted to evaluate the long term effects of wearing high heels.

\section{References}

[1.] Stewart, S.F., Footgear--its history, uses and abuses. Clin Orthop Relat Res, 1972. 88: p. 119-30.

[2.] Williams, C.M. and T.P. Haines, An exploration of emergency department presentations related to high heel footwear in Victoria, Australia, 2006-2010. Journal of foot and ankle research, 2014. 7(1): p. 4.

[3.] Busey, S., The influence of the constant use of high-heeled French shoes upon the health and form of the female, and upon the relation of the pelvic organs. Trans Am Gynecol Soc, 1882. 7: p. 261-263.

[4.] Treves, F., The influence of clothing on health. 1886: Cassell.

[5.] Frey, C., et al., American Orthopaedic Foot and Ankle Society women's shoe survey. Foot Ankle, 1993. 14(2): p. 78-81. 
[6.] Beynnon, B.D., et al., Ankle ligament injury risk factors: a prospective study of college athletes. Journal of Orthopaedic Research, 2001. 19(2): p. 213-220.

[7.] Cooke, M., et al., A survey of current consultant practice of treatment of severe ankle sprains in emergency departments in the United Kingdom. Emergency medicine journal, 2003. 20(6): p. 505-507.

[8.] Basmajian, J. and J. Bentzon, An electromyographic study of certain muscles of the leg and foot in the standing position. Surgery, gynecology \& obstetrics, 1954. 98(6): p. 662.

[9.] Younus, S.M., et al., HIGH HEEL SHOES; OUTCOME OF WEARING IN YOUNG GENERATION: A CROSS SECTIONAL STUDY. Professional Medical Journal, 2014. 21(4).

[10.] Ebbeling, C.J., J. Hamill, and J.A. Crussemeyer, Lower extremity mechanics and energy cost of walking in high-heeled shoes. Journal of Orthopaedic \& Sports Physical Therapy, 1994. 19(4): p. 190-196.

[11.] Foster, A., et al., The influence of heel height on frontal plane ankle biomechanics: implications for lateral ankle sprains. Foot \& ankle international, 2012. 33(1): p. 64-69.

[12.] Lee, C.-M., E.-H. Jeong, and A. Freivalds, Biomechanical effects of wearing high-heeled shoes. International journal of industrial ergonomics, 2001. 28(6): p. 321-326.

[13.] Moore, J.X., et al., Epidemiology of high-heel shoe injuries in US women: 2002 to 2012. The Journal of Foot and Ankle Surgery, 2015. 54(4): p. 615-619.

[14.] Ko, D.Y. and H.S. Lee, The changes of COP and foot pressure after one hour's walking wearing highheeled and flat shoes. Journal of physical therapy science, 2013. 25(10): p. 1309-1312.

[15.] Snow, R.E., K.R. Williams, and G.B. Holmes, The effects of wearing high heeled shoes on pedal pressure in women. Foot \& ankle, 1992. 13(2): p. 85-92.

[16.] Snow, R.E. and K.R. Williams, High heeled shoes: their effect on center of mass position, posture, threedimensional kinematics, rearfoot motion, and ground reaction forces. Archives of physical medicine and rehabilitation, 1994. 75(5): p. 568-576.

[17.] Hansen, A.H. and D.S. Childress, Effects of shoe heel height on biologic rollover characteristics during walking. Journal of rehabilitation research and development, 2004. 41(4): p. 547.

[18.] Guo, L.-Y., et al., Effect on plantar pressure distribution with wearing different base size of high-heel shoes during walking and slow running. Journal of Mechanics in Medicine and Biology, 2012. 12(01): p. 1250018 . 